\title{
API Supplier Change or Addition of Alterate API Supplier in Generic Drug Products: Cost, Quality and Regulatory Factors
}

Useni Reddy Mallu*, Arunkanth Krishnakumar Nair ${ }^{1}$, Hanimi Reddy Bapatu², Pavan Kumar M³ ${ }^{3}$ Santosh Narla ${ }^{4}$, Jonna Sankar ${ }^{4}$, Tejas ${ }^{4}$ Narendra Kumar Thamma ${ }^{4}$ and NVVSS Raman ${ }^{4}$

${ }^{1}$ Department of Chemistry, Sri Krishnadevaraya University, Anantapur, Andhra Pradesh, India

${ }^{2}$ Department of Chemistry, JNT University, Hyderabad, Andhra Pradesh, India

${ }^{3}$ Formulation Regulatory Affairs, Laurus Labs Pvt. Ltd, Hyderabad, India

${ }^{4}$ Hetero Drugs Ltd. (R\&D), Balanagar, Hyderabad, Andhra Pradesh, India

\begin{abstract}
Generic drug product (GDP) competition for market existence and profitability has become a challenging task for the manufacturers. All the generic players are putting intensive efforts to enter the market with competitive price and consistent drug product (DP) quality. The generic firms have to manage the delicate balance between the cost and quality of raw materials, especially the active pharmaceutical Ingredient (API) for market survival. Major Pharma companies have adopted the merger and acquisition strategies with API manufacturers to withstand the competition and price erosion. Still the majority firms don't have their own API manufacturing facility. Since the finished product cost is majorily driven by API, the supplier selection plays prominent role in the generic profitability as well as quality. The supplier screening and selection includes extensive evaluation and comparison of documents, quality and cost. As part of risk mitigation strategy many generic manufactures prefer to include additional or alternate sources for API supplier. This exercise could be triggered anytime during the DP life cycle. The authors have tried to share the view on supplier change process at various stages of product lifecycle and related regulatory authority requirements and expectations. Generic products have been targeted majorly for US and Europe regions and same is being focused here. These two regulatory bodies have almost similar requirement for supplier selection and change, except difference in procedural approaches. The regulatory requirements may vary for each phase of generic product life cycle. At the development stage, the supplier change may not significantly fall into regulatory umbrella. Generally development phase comes under relatively less regulatory scruitiny than CTD submission or post approval phase. The dossier review and post approval phase have almost similar regulatory requirements. All the post approval changes shall be routed through SUPAC filing in US and VARIATION filing procedures in Europe.
\end{abstract}

Keywords: API supplier selection; API supplier change; Alternative API supplier; SUPAC filing; Variation filing; Prior approval supplement; Type-II variation

\section{Introduction}

Pharmaceutical industry is growing exponentially in value and quantum year by year. Price competition as well as profitable trading has become a vital factor in the market existence for the companies across the globe. There has been consistent efforts and control by the regulatory authorities to maintain the product quality considering the end user safety. More legislations and regulations are being implemented emphasizing the quality standards with changing market scenario.

Every manufacturer has been putting their best efforts to overcome the shrinking revenues and profit margin. The material scarcity and cost are the significant barriers insisting the pharma companies to make compromises on product cost. The pharma companies have to manage a thin balance between cost and quality of raw materials which significantly impacts the finished DP quality attributes. The DP pricing structure reveals that the final cost is driven majorly by API price. This is most relevant for generic applicants, as the market is overcrowded and the profits are marginal.

Most of the pharma giants have their own API divisions to withstand the rapid price erosion. The pricing pressure is generally huge in the generic market due to the vast number of players. These diminishing margins and costing pressure leads to the lookout for cheaper API's by generic companies. As part of this the generic companies very frequently undergo API supplier changes to compete the market. The applicant has to go through regulatory process for supplier changes.
API manufacturers facing inspection failures owing to GMP (good manufacturing practices) non-compliance issues may also adversely affect the generic player's. This emphasizes the need for the right supplier selection for their DP development. Most of the inspection failures occur due to lack of online documentation, analytical compliance, procedural guidance implementation, deviations, CAPA (corrective action and preventive action), contamination, failures investigations and manufacturing problems etc. All these issues may insist to select right API supplier for generic drug development as well as to have additional API supplier as backup. The major focus of this write up is to make the reader aware of the existing regulatory expectations and strategies in carrying out the supplier change exercise.

\section{API Supplier Selection [1-3]}

Companies perform thorough evaluations based on individual internal systems and policies for selecting the appropriate API supplier.

*Corresponding author: Useni Reddy Mallu, Dept. of Chemistry, Sri Krishnadevaraya University, Anantapur, Andhra Pradesh, India; E-mail: drusenireddymallu@gmail.com

Received April 11, 2015; Accepted April 28, 2015; Published May 05, 2015

Citation: Mallu UR, Nair AK, Bapatu HR, Pavan Kumar M, Narla S, et al. (2015) API Supplier Change or Addition of Alterate API Supplier in Generic Drug Products: Cost, Quality and Regulatory Factors. Pharm Anal Acta 6: 364 doi:10.4172/21532435.1000364

Copyright: $\odot 2015$ Mallu UR, et al. This is an open-access article distributed under the terms of the Creative Commons Attribution License, which permits unrestricted use, distribution, and reproduction in any medium, provided the original author and source are credited. 


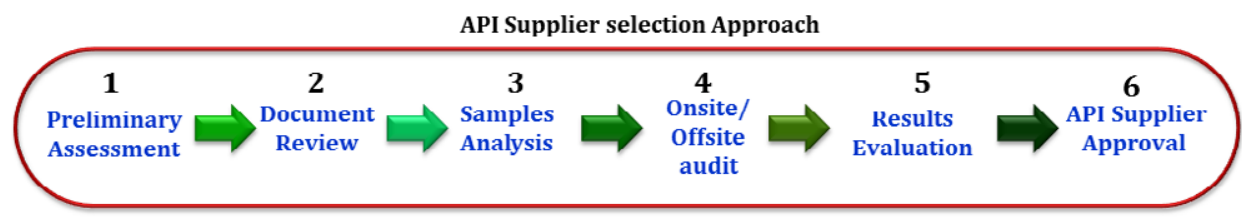

Figure 1: API supplier selection process [4-5].

API source selection will depend on a number of factors, including their familiarity with intended molecule or class of molecule, the strength of their Chemistry, Manufacturing and Controls (CMC) program (or the availability of CMC information for existing APIs), their ability to secure DMFs, history of regulatory inspections and manufacturing capabilities. The supplier selection process majorly comprises the document review, quality evaluation and cost comparisons. Purchase, quality assurance (QA), analytical, formulation and costing teams are the screening and evaluation cross functional teams majorly involved into selection process. Preferably, the API selection shall be initiated from a supplier pool which is audited and approved. Any new additional suppliers shall be audited by the selective quality teams. API supplier selection process has represented in the below Figure 1.

\section{Preliminary assessment}

API material properties and DP requirements should be understood. Generic product manufacturers should assess the initial assessment on each quality attributes.

\section{Document review}

Open part DMF should be reviewed and understood the synthetic route, product specifications, analytical procedure, impurity profile, stability results, and CMC changes.

\section{Sample analysis}

Supplier samples should be analyzed by using certified standard materials as per pharmacopoeial procedures (USP, Ph. Eur., JP or national pharmacopoeia) and/or in-house approved procedures.

\section{Onsite or off-site audit}

QA team should perform offsite or onsite audit activity. Inspection team should evaluate the API factory quality systems, deviations, CAPA, recalls, warning letters, reprocessing batches, annual reports, CMC changes, batch to batch variability, OOS, OOT, specifications and pharmacopoeial adoption etc.

\section{Summary data evaluation}

Supplier selection results should be evaluated of document review, sample analysis report and onsite/offsite audit results.

\section{API supplier approval or rejection}

Finally, two suppliers shall be selected one as main and another one as alterative supplier for generic DP development.

\section{API Supplier Change/Alternative Supplier Addition [6-7]}

As discussed in the above sections, generic product applicants consider a switch in API supplier mainly to control the manufacturing cost of the product, though the other reasons also may persist. The

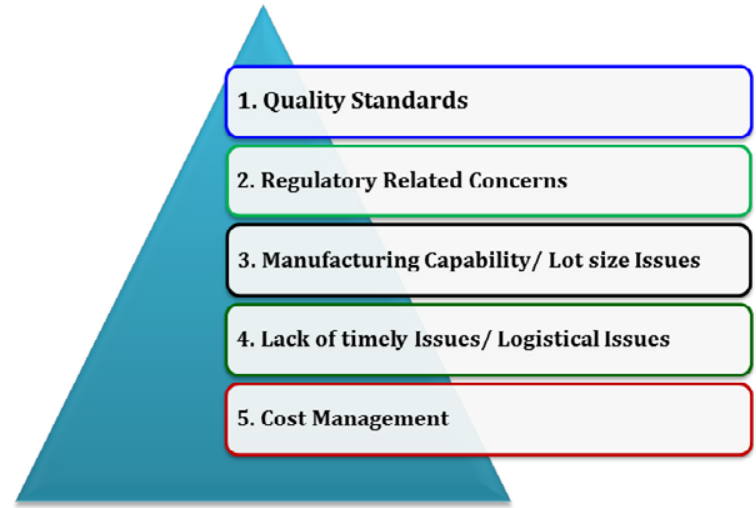

Figure 2: API supplier change or addition causes.

probable and most possible scenarios have been depicted below. Typically, on many occasions generic companies opt to go with more than one API suppliers during submission, which could enable the applicants to commercialize any of the approved suppliers in future 2 . The major geographies targeted by generic players are US and Europe owing to its huge market size and volume. Thus the article also primarily focused to cover the regulations and legislations related to supplier change procedures applicable to these domain (Figure 2).

The regulatory requirements may vary from phase to phase at which the supplier change happens. However if it occurs at development stage, the process may not undergo a thorough regulatory scrutiny or review as the product is neither submitted nor approved. Nevertheless, it is recommended to perform the quality comparisons as well as the risk assessments at these stages with the previous suppliers. The major causes for a suppliers change is listed below

API supplier selection shall be performed based on the appropriate evaluation process. However, change in supplier may happen at any stage of product life cycle, the possible reasons too could vary accordingly. Based on the general understanding and author's experience, the change phases can be classified as below,

\section{Development Phase}

2. Submission Phase

3. Review Phase (prior approval)

4. Post Approval Phase

\section{Development phase}

The product development stage can be further broadly divided into pre formulation, formulation (lab scale) and Formulation (pilot scale) stages. All these development phases fall before the exhibit batch or 
dossier submission stages and thus the changes or addition of suppliers at this stage may not be considered under regulatory umbrella. Most of the time the supplier change or addition at these stages shall be approached similarly. Regulatory bodies generally expect to have the experiments repeated with new API material. Below table represented the development phases and redevelopment activities [8] Table 1.

Step 1: Pre-formulation: Pre-formulation includes characterization of API, reference medicinal products, excipients compatibility and preliminary formulation experiments. If API supplier change happens after completion of Preformulation studies, generic player should repeat all the pre-formulation activities with new API material, such as characterization of API and excipients compatibility studies. Again redefine the CMA for new API material and risk assessment should be performed.

Step 2: Formulation (Lab Scale): Step-2 includes evaluating and establishing QbD (quality by design) elements like CQA, CMA, DoE (design of experiments) and design space (DS) in lab scale level. This step carries significant role in the DP development and so the vendor change risks from API material quality attributes on quality attributes need to be thoroughly evaluated. Thus, it's advisable to perform the risk assessments with API supplier change and repeat the formulation experiments to mitigate the risks and ensure the control strategies.

Step 3: Formulation (Pilot Scale): This step includes design space and control strategy on formulation, specifications and analytical procedures. If API supplier has changed then all previous development activities should perform including stability studies. Comparison report may also require for both API material physicochemical properties such as synthesis, impurities profile, residual solvents, polymorphism, water content, Flowability etc.

If API supplier change happens at this stage then the GDP manufacturer should work for additional developmental activities (Figure 3). The dissolution comparisons along with other CQA's shall be ensured before switching over to new API supplier. It is expected to enclose all these experiments and updates with relevant data in the product development report. The associated risk assessments along with mitigation strategies for the DP quality attributes shall also need to be updated in the report.
Addition of alternative API supplier: Generic manufacturer can add alternative API material for DP. A comparison report on both APIs physical and chemical properties including starting materials, impurity profile, residual solvents, specifications and analytical procedures is recommended. Generic applicant should discuss all experimental data in product development report.

\section{Submission phase}

Submission phase includes exhibit or submission (pivotal) batch manufacturing, BABE (bio-availability and bio-equivalence) studies, stability studies, CTD (common technical document) preparation and submission. Generic product manufactures can choose an alternative source of API at the commercial stage or even change the existing API supplier as well. Figure 4 represents all activities in this phase.

The supplier additions at this stage have to be routed through regulatory purview and the associated recommendations and requirements have been established by the regulatory bodies. Adequate risk assessments along with mitigations and control strategies should be established and reported. Simultaneously all the regulatory bodies recommend for DP in-vitro dissolution comparisons and similarity between the suppliers. If any discrepancies or failures in exhibit batches stability studies or bioequivalence studies, then the DP may undergo redevelopment.

Addition of alternate API supplier: Regulatory authority expectations are similar to primary and alternate sources of API Subsequently, the product development report shall carry adequate information to support the alternate supplier selection and adoption. In addition, a comparison report between primary API and other sources on the synthetic route, process, impurity profile and physicochemical properties is also recommended. Alternative API sourced manufactured batches BE studies were waived on conditions of in-vitro similarities. CTD DS part should carry details about both the API sourced materials. The below CMC data shall be included in the dossier if intend to submit alternative API sources for the DP.

I. Comparison and justification of the comparability of the physical and chemical properties (starting material, impurities, assay etc.) of DS from each source

\begin{tabular}{|c|c|}
\hline Product development steps & Redevelopment activity requirement \\
\hline Step-1: Pre-formulation & Comparison of API specifications, Polymorphs, Monographs compliance, Physical and chemical characterisation. \\
\hline Step-3: Formulation (Pilot scale) & $\begin{array}{l}\text { 1. Perform the Step } 1 \text { activities } \\
\text { 2. Re-evaluate the drug substance (DS) and DP risk assessments } \\
\text { 3. Re assess the QTPP,CQA,CMA (critical material attributes),CPP (critical process parameters) and design space } \\
\text { 4. Evaluate the DP stability }\end{array}$ \\
\hline
\end{tabular}

Table 1: API supplier change requirements at various development stage.

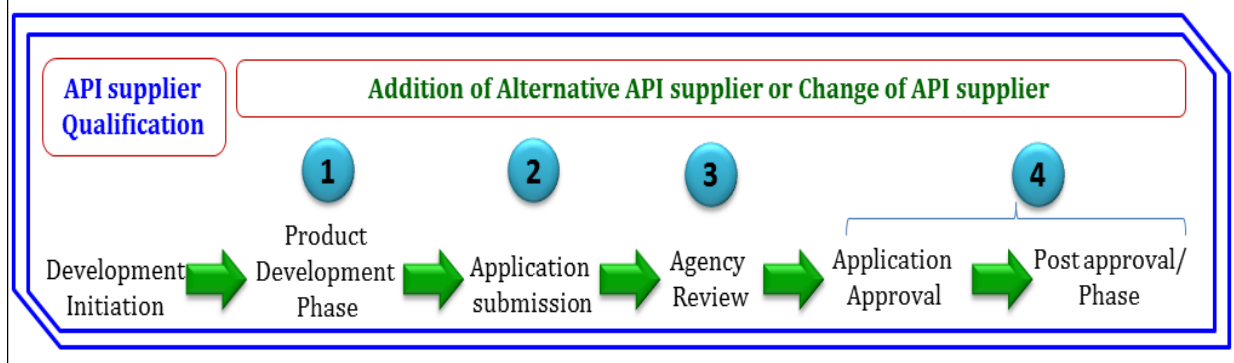

Figure 3: GDP life cycle with API supplier selection, change or addition. 


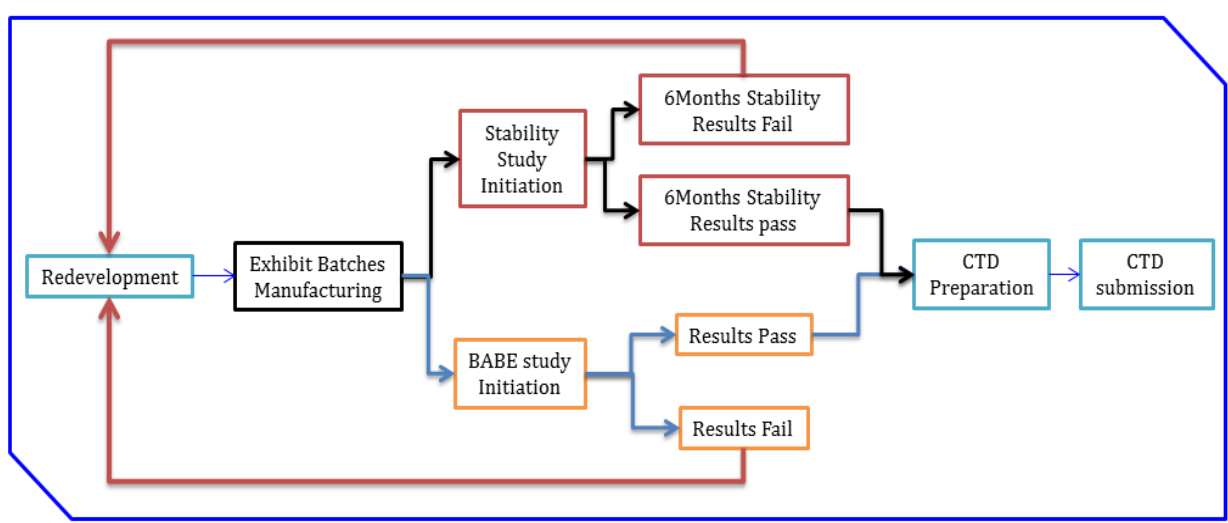

Figure 4: Submission phase activities and approach [9-14]

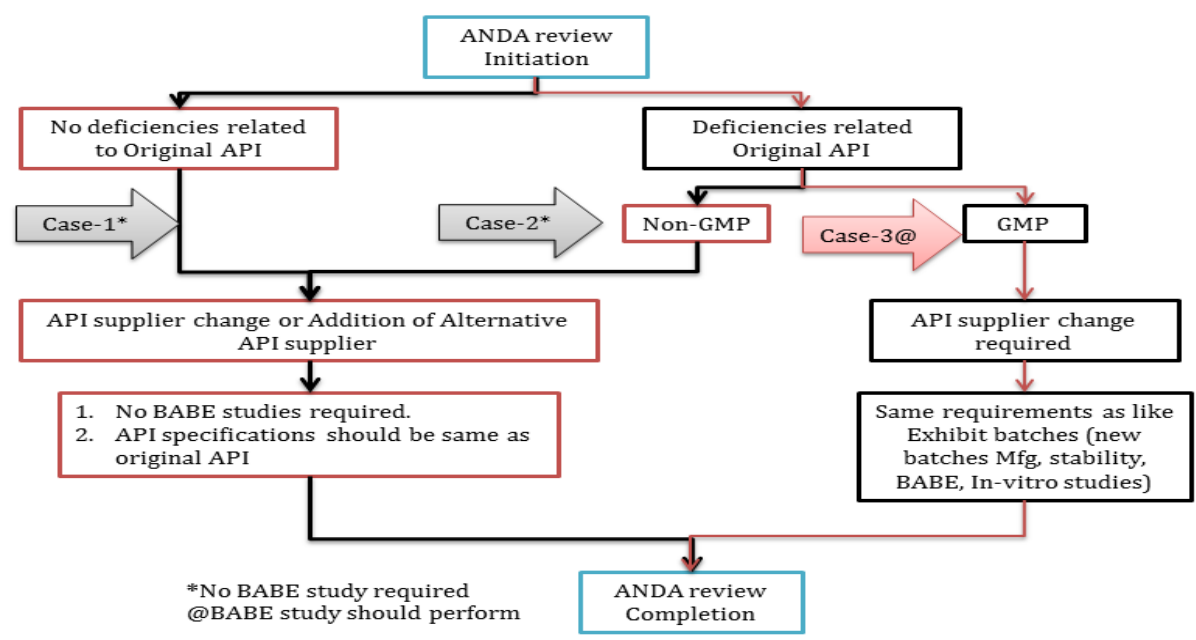

Figure 5: Change or addition of alternative API supplier in review phase.

II. Separately manufactured DP batches with alternative API material.

III. Comparative dissolution data with the first supplier

IV. Appropriate stability data on each strengths manufactured using alternative API source.

\section{Review phase (Prior approval) [15-17]}

Generic companies may proceed for API supplier change or addition of alternative supplier in the review period. Applicant should submit amendment or supplement to agency for change or addition of API supplier. USFDA has published the guidance on "Alternative source of active pharmaceutical ingredient in pending ANDAs". Figure 5 has represented the approaches for API supplier change or addition in the review period. As per figure 5, authors has considered three cases such as,

* Case 1: No API related deficiencies from reviewer

- Case 2: Non-GMP deficiencies received on original API

* Case 3: GMP deficiencies received on original API
Case 1: No API related deficiencies from reviewer: If no major deficiency received on present API material, then generic applicant can proceed for API supplier change or addition of new API supplier with minimum documentation and regulatory burden. Generic applicant should perform the equivalency between present and proposed API suppliers, not limited to physicochemical properties. No BABE studies are required in this case, but API finished specifications should be similar with primary API material. For any mismatches with present API, then suitable scientific justification may be accepted. Other requirements are same as prior approval supplement including new batch and stability studies with proposed API material. Detailed discussion represented in below section (Post approval phase).

Case 2: Non-GMP deficiencies received on original API: This category includes the case where the DS deficiencies were received from agency other than GMP. In this case also generic applicant may not have to perform bioequivalence studies for API supplier change or addition. Similar to case-1 requirements, comparison report between the API's is required. Other requirements are same as prior approval supplement including new batch and stability studies with proposed API material. Detailed discussion represented in below section (Post approval phase). 


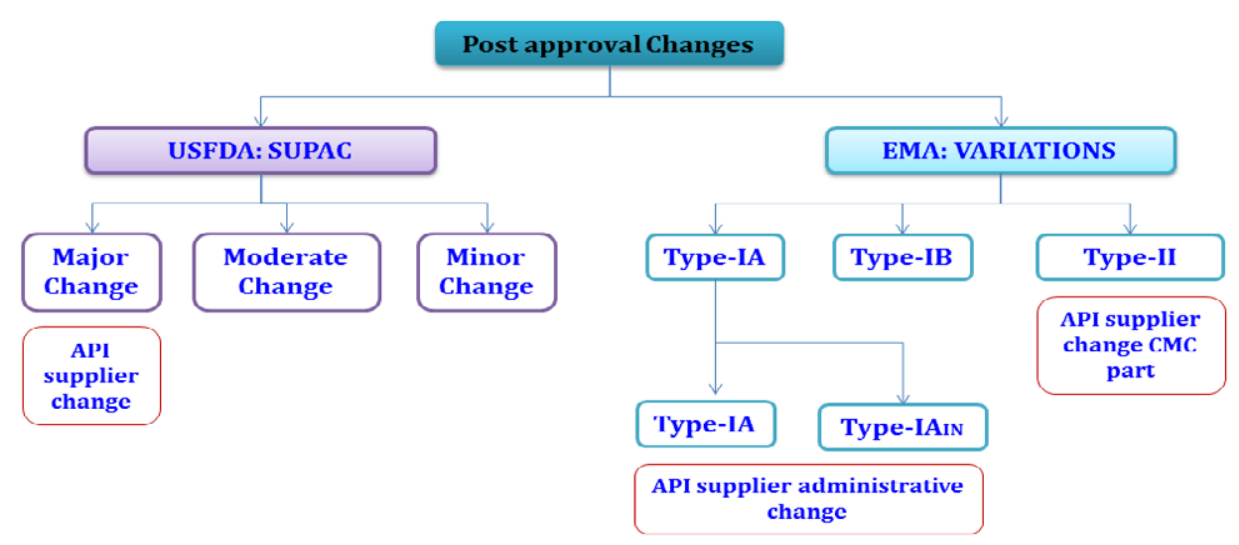

Figure 6: Post approval process in USFDA and EMA.

Case 3: GMP deficiencies received on original API: The API source variation or additions at ANDA review phase shall undergo substantial regulatory scrutiny. The supplier changes due to GMP issues related to the primary API manufacturer may call for new bioequivalence studies. Generic player should manufacture new submission batches and perform the 6 months stability and bioequivalence studies. In-vitro studies also needed with new API material. Previous bioequivalence studies (submitted batches) were acceptable except for the GMP issues that were specific to the original API. The specifications of the alternate source API need to be essentially same as the original source API. Applicant should assure the similarity in synthesis, impurity profile and physicochemical properties between original and alternate source of API.

Further the applicant needs to confirm that the original API source is not being withdrawn due to deficiencies specifically relating to that API such as, lack of adequate controls; evidence of adulteration and evidence of falsification of data in the application or identified in the preapproval inspection. If these three situations apply, a new acceptable BABE study and comparative dissolution data for all strengths will be needed to support the alternate source for API.

Regulatory framework demands the applicant to follow prior approval for API supplier change or addition of alternative API supplier. More precisely, USFDA recommending proceeding with PAS and EMA recommends similar procedure, type- 2 variation approach (described in below section)

\section{Post approval phase [18-26]}

The Post approval period could be broadly classified into before and after commercialization. Either of these stages generic manufactures could force for an API supplier change or addition. Irrespective of the stage, the regulatory demands and procedures are similar and insist to abide by the published guidances. Typically, a change from one DS manufacturer to another involves more than simply a site change. In most cases, there will be additional differences (e.g., route of synthesis, process, impurities, residual solvents, and equipment) which have to be addressed adequately. Nevertheless, regulatory agencies recommend for submitting the comprehensive information for both the DSs. Post approval phase changes requirements are different for USFDA and EMA. All post approval changes will be handled in US with SUPAC filing approach and for Europe VARIATION filing procedure. Figure 6 represents the USFDA and Europe post approval categories with API supplier change or alternative supplier change.

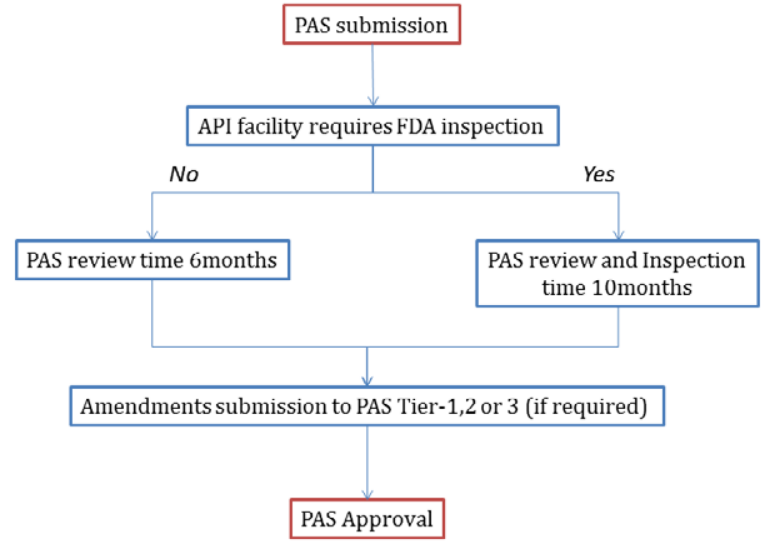

Figure 7: USFDA prior approval supplement procedure.

\section{USFDA perspective}

API supplier change or addition of alternative supplier is belongs to major change so generic applicant should proceed with prior approval supplement [PAS] (Figure 7).

\section{Major changes (PAS)}

Manufacturing sites: A move to a different manufacturing site, except one used to manufacture or process a DS intermediate, when the new manufacturing site has never been inspected by FDA for the type of operation that is being moved or the move results in a restart at the new manufacturing site of a type of operation that has been discontinued for more than two years.

A move to a different manufacturing site, except one used to manufacture or process a DS intermediate, when the new manufacturing site does not have a satisfactory cGMP inspection for the type of operation being moved. A move to a different manufacturing site for the manufacture, processing, or primary packaging of DPs when the primary packaging

Manufacturing process: Any fundamental change in the manufacturing process or technology from that currently used by the applicant. DS: Change in the route of synthesis of a DS. Changes in the 
Citation: Mallu UR, Nair AK, Bapatu HR, Pavan Kumar M, Narla S, et al. (2015) API Supplier Change or Addition of Alterate API Supplier in Generic Drug Products: Cost, Quality and Regulatory Factors. Pharm Anal Acta 6: 364. doi:10.4172/21532435.1000364

Page 6 of 8

synthesis or manufacture of the DS that may affect its impurity profile and/or the physical, chemical, or biological properties.

\section{PAS filing Procedure}

Change or addition of API supplier belongs to major change and thus routed through PAS (Prior Approval supplement) submission procedure. ANDA applicant should submit the PAS to the agency with GDUFA (Generic Drug User Fee Act) fee. As per GDUFA, the PAS review completion target is $6 \mathrm{months}$ and if the new API manufacturing facility requires FDA inspection then the review time shall be 10months. The review completion timelines may vary from 6 months to 10months based on the FDA decision on API site inspection. FDA will provide notice to the applicant if such a change arises. As noted above, if an amendment is made to a PAS, the GDUFA goal date associated with that PAS may be revised. Amendments are classified into Tier-1, Tier -2 and Tier -3 categories. Based on the amendment nature PAS review time will be revised. These all changes and supplements are discussed in FDA guidance "ANDA submissions-amendments and easily correctable deficiencies under GDUFA" ; "ANDA submissionsPrior approval supplements under GDUFA" and "Major, Minor and Telephone amendments to Abbreviated New Drug Applications"

\section{EMA perspective}

API supplier change or addition of alternative supplier falls to variation type-IA administrative changes (manufacturer name,

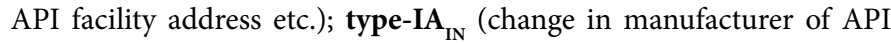
where no CEP [certificate of suitability of monographs of European pharmacopoeia]) and variation type-II (API synthetic route, impurities, specifications etc.). These two variation filing approaches details are tabulated in the below. If the API doesn't have approved CEP/ASMF (active substance master file) then generic applicant should follow the EMA recommended procedures Table 2.

Type-IA variation: This is an administrative change variation category and the details were tabulated in the below table.

Type-II variation (Quality changes): (Change in the manufacturer (including where relevant quality control testing sites) of the active substance (AS), where no Ph. Eur. certificate of suitability is part of the approved dossier)

\section{Definition}

Sub Section-1 (B.I.a.1.b): Introduction of a manufacturer of the AS supported by an ASMF

Sub Section-2 (B.I.a.1.b): The proposed manufacturer uses a substantially different route of synthesis or manufacturing conditions, which may have a potential to change important quality characteristics of the AS, such as qualitative and/or quantitative impurity profile requiring qualification, or Physico-chemical properties impacting on bioavailability

Sub Section-3 (B.I.a.1.b): Introduction of a new manufacturer of the AS that is not supported by an ASMF and requires significant update to the relevant AS section of the dossier.

Variation filing Procedure: Variations handling procedure can depend on the application procedure i.e. Centralized, National and Mutual recognition procedures. These variations can be followed as per EU variation guidance "Guideline on the details of the various categories of variations to the terms of marketing authorizations for medicinal products for human use and veterinary medicinal products" and other. Authors have previously published the article on "Variation filing procedure in Europe: A complete review"

\section{Documentation for Regulatory Agencies [27-38]}

API supplier change or addition of alternative supplier has similar requirements for documentation submission. USFDA and EMA agencies have similar CMC requirements and administrative requirements are different for each regulatory agency. In CTD module-1 is belongs to administrative information so it has different requirements for each agency. Table 3 has represented the module-1 requirements. CMC changes have similar requirements for both regulatory bodies and the detailed documentation requirements were tabulated in Table 4.

\section{Conclusion}

The API supplier change or addition of alternative supplier may happen anytime during the generic DP lifecycle. The regulatory guidances majorly concentrate on the post approval supplier changes and up to some extent in development and submission phase also. However, there is still lack of clarity on the regulatory expectations for API supplier change or addition of alternative API supplier during development stages. If these changes occur before CTD submission,

Type-IA variation (Administrative changes)-A.4.

Definition: Change in the name and /or address of a manufacturer or an ASMF holder or a supplier of the API, starting material where no Ph. Eur. certificate of suitability is part of the approved dossier.

Required documentation:

1. A formal document from a relevant official body (eg. chamber of commerce) in which the new and/or address is mentioned

2. Amendment of the relevant sections of the dossier

3. In case of change in the name of the holder of the API holder, updated letter of access.

Type-IA ${ }_{\mathrm{IN}}$ variation (quality change)-B.I.a.1.a

(Change in the manufacturer (including where relevant quality control testing sites) of the active substance (AS), where no Ph. Eur. certificate of suitability is part of the approved dossier)

Definition: The proposed manufacturer is part of the same pharmaceutical group as the currently approved manufacturer

Required documentation:

1. Amendment of the relevant sections of the dossier.

2. A declaration on similarity of API synthetic route, specifications and test procedure for both API suppliers.

3. Either a TSE Ph. Eur. certificate of suitability for any new source of material (where applicable).

4. Batch analysis data for at least two batches (minimum pilot scale) of the API from the current and proposed manufacturers/sites.

5. Detailed information in Module-1, 1.2 Application form, section 2.5 outline the 'present' and 'proposed' manufacturers.

6. QP declaration for each of API manufacturing facility.

Table 2: EMA type-I variaton changes. 
Citation: Mallu UR, Nair AK, Bapatu HR, Pavan Kumar M, Narla S, et al. (2015) API Supplier Change or Addition of Alterate API Supplier in Generic Drug Products: Cost, Quality and Regulatory Factors. Pharm Anal Acta 6: 364. doi:10.4172/21532435.1000364

Page 7 of 8

\begin{tabular}{|c|l|}
\hline $\begin{array}{c}\text { Document title } \\
\text { API GMP and } \\
\begin{array}{c}\text { Administrative information } \\
\text { (if unaudited facility) }\end{array}\end{array}$ & $\begin{array}{l}\text { GMP Related: Recalls, OOS/OOT, CAPA, deviations, facility inspection failures (if any), recent regulatory inspections and warning letters/ } \\
\text { import alerts. } \\
\text { Administrative: New API holder DMF letter of access, API facility inspection declaration letter (EU), QP declaration letter (EU), APIs } \\
\text { establishment inspection report and Supply capacity and Material price statement. Patents certification (if required) }\end{array}$ \\
\hline Module-1 & $\begin{array}{l}\text { USFDA: Form-356 h; cover letter, API DMF document letter of authorization; request for Biowaiver (if applicable). } \\
\text { EMA: cover letter, application form [annexures for new API supplier information including facility and corporate office address, Brief } \\
\text { description of API manufacturing process, Description of GMP facility, GMP certificates and qualified person for batch release declaration } \\
\text { letters] and product related information. }\end{array}$ \\
\hline
\end{tabular}

Table 3: Documentation requirements for adimistrative part.

\begin{tabular}{|c|l|}
\hline $\begin{array}{c}\text { Document title } \\
\begin{array}{c}\text { Comparison report on both } \\
\text { APIs }\end{array}\end{array}$ & $\begin{array}{l}\text { Synthetic route (starting material, impurities profile, residual solvents), Physical properties (particle size, bulk density, polymorphism, } \\
\text { solubility), Specifications, Analytical procedures and Method validation }\end{array}$ \\
\hline DP development & $\begin{array}{l}\text { Comparison report for API physicochemical properties, DP impurity profile, Updated components and composition statement, analytical } \\
\text { method validation reports. Risk assessments and QbD elements reconfirmation. }\end{array}$ \\
\hline $\begin{array}{c}\text { New manufacturing batches } \\
\text { with proposed API }\end{array}$ & $\begin{array}{l}\text { Intended master batch records for the largest intended commercial batch size (US), Executed batch manufacturing record (for USFDA), } \\
\text { Batch analysis CoA, in-vitro dissolution results, in-vitro dissolution comparison report with old API mfg. batches, 6months accelerated and } \\
\text { long term stability data and stability commitment for long term/intermediate conditions. }\end{array}$ \\
\hline CTD sections & DS CMC part: Module-2 QOS and Module-3 DS part \\
\hline
\end{tabular}

Table 4: Documentation requirements for quality part.

the recommendations are to discuss in DP development report. Development report should carry the comparison between both APIs including physicochemical properties and formulation attributes. The post approval phase changes shall be routed through prior approval supplements for USFDA applications or variations filing procedure for Europe applications. For pending generic applications, vendor change due to any API GMP related deficiency, then a bioequivalence studies need to be performed. Based on the recent developments, the QbD tools and risk assessments shall be appropriately used to support all these changes. Global regulatory and quality standards are expected to maintain by DP manufacturers throughout the product life cycle irrespective of the API sources.

\section{References}

1. Currey JD (1975) The effects of strain rate, reconstruction and mineral conten on some mechanical properties of bovine bone. J Biomech 8: 81-86.

2. Peterlik H, Roschger $P$, Klaushofer K, Fratzl $P$ (2006) From brittle to ductile fracture of bone. Nat Mater 5: 52-55.

3. Seeman E, Delmas PD (2006) Bone quality--the material and structural basis of bone strength and fragility, N Engl J Med 354: 2250-2261.

4. Kruzic JJ, Ritchie RO (2008) Fatigue of mineralized tissues: cortical bone and dentin. J Mech Behav Biomed Mater 1: 3-17.

5. Dempster DW (2002) The impact of bone turnover and bone-active agents on bone quality: focus on the hip. Osteoporos Int 13: 349-352.

6. Boivin GY, Chavassieux PM, Santora AC, Yates J, Meunier PJ (2000) Alendronate increases bone strength by increasing the mean degree of mineralization of bone tissue in osteoporotic women. Bone 27: 687-694.

7. Nuzzo S, Peyrin F, Cloetens P, Baruchel J, Boivin G (2002) Quantification of the degree of mineralization of bone in three dimensions using synchrotron radiation microtomography. Med Phys 29: 2672-2681.

8. Boivin G, Lips P, Ott SM, Harper KD, Sarkar S, et al. (2003) Contribution of raloxifene and calcium and vitamin D3 supplementation to the increase of the degree of mineralization of bone in postmenopausal women. J Clin Endocrino Metab 88: 4199-4205.

9. Boivin G, Vedi S, Purdie DW, Compston JE, Meunier PJ (2005) Influence of estrogen therapy at conventional and high doses on the degree of mineralization of iliac bone tissue: a quantitative microradiographic analysis in postmenopausal women, Bone 36: 562-567.

10. Borah B, Ritman EL, Dufresne TE, Jorgensen SM, Liu S (2005) The effect of risedronate on bone mineralization as measured by micro-computed tomography with synchrotron radiation: correlation to histomorphometric indices of turnover, Bone 37: 1-9.
11. Borah B, Dufresne TE, Ritman EL, Jorgensen SM, Liu S (2006) Long-term risedronate treatment normalizes mineralization and continues to preserve trabecular architecture: sequential triple biopsy studies with micro-computed tomography, Bone 39: 345-352

12. Bauss F, Dempster DW (2007) Effects of ibandronate on bone quality: preclinical studies. Bone 40: 265-273.

13. (2005) Fast facts on osteoporosis, National Osteoporosis Foundation

14. Davignon J (2004) Beneficial cardiovascular pleiotropic effects of statins. Circulation 109: III39-43.

15. Kwak B, Mulhaupt F, Myit S, Mach F (2000) Statins as a newly recognized type of immunomodulator. Nat Med 6: 1399-1402.

16. Benoit B, Gofton W, Beaulé PE (2009) Hueter anterior approach for hip resurfacing: assessment of the learning curve. Orthop Clin North Am 40: 357-363.

17. Kanazawa I (2009) Usefulness of metformin in diabetes-related bone disease Clin Calcium 19: 1319-1325.

18. Fogh J, Fogh JM, Orfeo T (1977) One hundred and twenty-seven cultured human tumor cell lines producing tumors in nude mice. J Natl Cancer Inst 59 221-226.

19. Rodan SB, Imai Y, Thiede MA, Wesolowski G, Thompson D, et al. (1987) Characterization of a human osteosarcoma cell line (Saos-2) with osteoblastic properties. Cancer Res 47: 4961-4966.

20. Hausser HJ, Brenner RE (2005) Phenotypic instability of Saos-2 cells in longterm culture. Biochem Biophys Res Commun 333: 216-222.

21. Hamidi M, Zarei N, Shahbazi MA (2009) A simple and sensitive HPLCUV method for quantitation of lovastatin in human plasma: application to a bioequivalence study. Biol Pharm Bull 32: 1600-1603.

22. Keskitalo JE, Pasanen MK, Neuvonen PJ, Niemi M (2009) Different effects of the ABCG 2 c.421C>A SNP on the pharmacokinetics of fluvastatin, pravastatin and simvastatin. Pharmacogenomics 10: 1617-1624.

23. Stern RH, Yang BB, Hounslow NJ, MacMahon M, Abel RB (2000) Pharmacodynamics and pharmacokinetic-pharmacodynamic relationships of atorvastatin, an HMG-CoA reductase inhibitor, J Clin Pharmacol 40: 616-623.

24. Bu DX, Tarrio M, Grabie N, Zhang Y, Yamazaki H (2010) Statin-induced Kruppel-like factor 2 expression in human and mouse $T$ cells reduces inflammatory and pathogenic responses, J Clin Invest 120: 1961-1970.

25. Chow OA, von Köckritz-Blickwede M, Bright AT, Hensler ME, Zinkernagel AS et al. (2010) Statins enhance formation of phagocyte extracellular traps. Cell Host Microbe 8: 445-454.

26. Kureishi Y, Luo Z, Shiojima I, Bialik A, Fulton D, et al. (2000) The HMG-CoA reductase inhibitor simvastatin activates the protein kinase Akt and promotes angiogenesis in normocholesterolemic animals. Nat Med 6: 1004-1010. 
Citation: Mallu UR, Nair AK, Bapatu HR, Pavan Kumar M, Narla S, et al. (2015) API Supplier Change or Addition of Alterate API Supplier in Generic Drug Products: Cost, Quality and Regulatory Factors. Pharm Anal Acta 6: 364. doi:10.4172/21532435.1000364

27. Weitz-Schmidt G, Welzenbach K, Brinkmann V, Kamata T, Kallen J (2001) Statins selectively inhibit leukocyte function antigen-1 by binding to a novel regulatory integrin site, Nat Med 7: 687-692.

28. Youssef S, Stuve O, Patarroyo JC, Ruiz PJ, Radosevich JL (2002) The HMGCoA reductase inhibitor, atorvastatin, promotes a Th2 bias and reverses paralysis in central nervous system autoimmune disease, Nature 420: 78-84.

29. Somjen D, Kohen F, Lieberherr M, Gayer B, Schejter E (2005) Membranal effects of phytoestrogens and carboxy derivatives of phytoestrogens on human vascular and bone cells: new insights based on studies with carboxy-biochanin A, J Steroid Biochem Mol Biol 93: 293-303.

30. Katzburg S, Lieberherr M, Ornoy A, Klein BY, Hendel D, et al. (1999) Isolation and hormonal responsiveness of primary cultures of human bone-derived cells: gender and age differences. Bone 25: 667-673.

31. Fromigué O, Haÿ E, Modrowski D, Bouvet S, Jacquel A, et al. (2006) RhoA GTPase inactivation by statins induces osteosarcoma cell apoptosis by inhibiting p42/p44-MAPKs-Bcl-2 signaling independently of BMP-2 and cell differentiation. Cell Death Differ 13: 1845-1856.

32. Kato S, Smalley S, Sadarangani A, Chen-Lin K, Oliva B, et al. (2010) Lipophilic but not hydrophilic statins selectively induce cell death in gynaecological cancers expressing high levels of HMGCoA reductase. J Cell Mol Med 14 $1180-1193$.
33. Hamelin BA, Turgeon J (1998) Hydrophilicity/lipophilicity: relevance for the pharmacology and clinical effects of HMG-CoA reductase inhibitors. Trends Pharmacol Sci 19: 26-37.

34. Pfefferkorn JA, Song Y, Sun KL, Miller SR, Trivedi BK (2007) Design and synthesis of hepatoselective, pyrrole-based HMG-CoA reductase inhibitors, Bioorg Med Chem Lett 17: 4538-4544.

35. White CM (1999) Pharmacological effects of HMG CoA reductase inhibitors other than lipoprotein modulation. J Clin Pharmacol 39: 111-118.

36. Cafforio P, Dammacco F, Gernone A, Silvestris F (2005) Statins activate the mitochondrial pathway of apoptosis in human lymphoblasts and myeloma cells. Carcinogenesis 26: 883-891.

37. Karp I, Behlouli H, Lelorier J, Pilote L (2008) Statins and cancer risk. Am J Med 121: 302-309.

38. Katz MS (2005) Therapy insight: Potential of statins for cancer chemoprevention and therapy. Nat Clin Pract Oncol 2: 82-89.

39. Sugiyama M, Kodama T, Konishi K, Abe K, Asami S, et al. (2000) Compactin and simvastatin, but not pravastatin, induce bone morphogenetic protein-2 in human osteosarcoma cells. Biochem Biophys Res Commun 271: 688-692.

40. Klein BY, Rojansky N, Ben-Yehuda A, Abou-Atta I, Abedat S, et al. (2003) Cell death in cultured human Saos2 osteoblasts exposed to low-density lipoprotein. J Cell Biochem 90: 42-58. 